\title{
In vitro digestibility of different prey species of minke whales (Balaenoptera acutorostrata)
}

\author{
BY ERLING S. NORDØY, WENCHE SØRMO \\ AND ARNOLDUS SCHYTTE BLIX \\ Department of Arctic Biology and Institute of Medical Biology, University of Tromse, \\ Tromso, Norway
}

(Received 24 March 1992 - Accepted 5 October 1992)

\begin{abstract}
Information on diet composition, daily energy expenditure, energy storage and the utilization of energy in the prey are important factors when evaluating the food consumption of minke whales (Balaenoptera acutorostrata) during their summer stay in northern waters. The purpose of the present study was in this context to obtain information on the digestible energy (DE) of different prey selected by minke whales. An in vitro three-stage digestion technique, simulating the different compartments of the digestive system, has been developed. The initial step simulated the anaerobic microbial fermentation of substrate in the forestomach. The next stage included the addition of pepsin $(E C$ 3.4.23.1)-HCl, simulating ventricle enzymic decomposition, and finally, in the third step, fresh extract from duodenal contents was used to simulate enzymic intestinal degradation of the remaining components of the food. The inoculum was normally obtained from animals which had recently eaten the prey to be tested. In such tests we obtained a dry matter disappearance (DMD) and a DE for herring (Clupea harengus) of 80.4 (SD 5.0) \% ( $n$ 18) and 92.1 (SD 3.7) \% (n 16) respectively, and a DMD of krill (Thysanoessa Sp.) of 83.4 (SD 4.9) \% $(n$ 6). The DMD of krill was reduced to $73.8(\operatorname{sD~} 7.3) \%(n 8)$ while the DE was $70.6(\operatorname{sD~} 10.4) \%(n 7)$ when inoculum from whales which had recently eaten cod (Gadus morhua) and haddock (Melanogrammus aeglefinus) was used. These results indicate a high digestibility of the most common species of prey in these animals, and also that the whales have little difficulty in changing from one prey species to another.
\end{abstract}

Digestible energy: Dry matter disappearance: Minke whales

Assuming a population of about 80000 minke whales (Balaenoptera acutorostrata) in Norwegian waters (Øien, 1991; Schweder et al. 1991) it is important to know what and how much all these animals eat for proper management of both fish and whales. In evaluating the food requirements of the whales it is, among other things, necessary to know the digestibility of the different prey they choose to eat (Nordøy \& Blix, 1992). Harp seals (Phoca groenlandica), which inhabit much the same waters and eat much the same food, have been extensively studied. Their ability to digest a variety of food is well known, but seals are single-stomached animals, while minke whales depend to a great extent on microbial fermentation in a multi-stomach system (Mathiesen et al. 1990; Olsen et al. 1993), and findings from seals, therefore, have little application for baleen whales. This probably is particularly true when it comes to digestion of crustaceans, since we have shown that minke whales are rich in chitinase (EC 3.2.1.14)-producing microbes in their forestomachs (Mathiesen et al. 1990).

Unlike seals and small cetaceans, baleen whales are difficult to keep in captivity for experimental purposes. Based on anatomical and bacteriological examinations of the digestive system of minke whales (Mathiesen et al. 1990) we have consequently developed a three-stage in vitro technique which is, in principle, a combination of the two-stage procedure of Tilley \& Terry (1963) for ruminants and the two-stage in vitro technique for 
the single-stomached pig (Furaya et al. 1979), for evaluation of food digestibility in minke whales. First, fresh inoculum from the forestomach of minke whales is used to mimic the initial bacterial degradation of the substrate. Second, pepsin $(E C 3.4 .23 .1)-\mathrm{HCl}$ is added to simulate the digestion in the fundic chamber (ventricle), and finally, extract of duodenal contents is added to imitate intestinal enzymic decomposition of the remaining organic matter. The dry matter is then isolated and compared with the initial dry matter content of the substrate for estimation of dry matter disappearance (DMD), and subsequently the energy contents of the substrate and the residual dry matter are determined by bomb calorimetry for estimation of digestible energy (DE).

\section{MATERIALS AND METHODS}

A total of six mature minke whales of both sexes from the north-eastern Atlantic stock were used in the present study.

A laboratory fully equipped with centrifuges, incubators, warm baths, coolers, freezers and other necessary equipment was established aboard a whaling vessel as part of the Norwegian scientific whaling programme in 1989 and 1990. A series of experiments was performed on samples from an animal which had recently eaten krill (Thysanoessa sp.) off Spitsbergen and on animals which had recently eaten herring (Clupea harengus), cod (Gadus morhua) and haddock (Melanogrammus aeglefinus) off Northern Norway. Fresh samples of krill and herring were obtained by trawling at the same locations.

\section{Preparation of forestomach inoculum}

Fresh forestomach contents of recently caught minke whales were collected, filtered through doubly layered gauze cloth, and diluted 1:4 (v/v) with a physiological buffer (Løwgren et al. 1989) giving a concentration of culturable viable bacteria in the order of $10^{9} \mathrm{cells} / \mathrm{ml}$ in the final inoculum. Before use the inoculum was gassed with $\mathrm{CO}_{2}$ to obtain a $\mathrm{pH}$ between 6.7 and 6.9 .

\section{Preparation of duodenum extract}

About 1 litre fresh duodenal contents was collected from the same minke whale, and diluted $1: 1(\mathrm{v} / \mathrm{v})$ with a physiological buffer (Lowgren et al. 1989) and mixed by shaking. The solution was then poured into $50 \mathrm{ml}$ polyethylene vials and centrifuged for $10 \mathrm{~min}$ at $2500 \mathrm{~g}$. The supernatant fraction was collected in an Erlenmeyer flask and stored at $5^{\circ}$ until use.

\section{In vitro digestion procedure}

Between 4 and $10 \mathrm{~g}$ freshly thawed krill or cut herring was weighed (accuracy $\pm 0 \cdot 1 \mathrm{mg}$ ) into $250 \mathrm{ml}$ Erlenmeyer flasks and $50 \mathrm{ml}$ forestomach inoculum from a whale which had recently eaten the prey to be tested was added to each flask. The $\mathrm{pH}$ of the inoculum before incubation, ranging between 6.7 and 6.9 , was within the range of that measured in the forestomach content ( $\mathrm{pH} 5 \cdot 36-6 \cdot 99)$. In two separate cases inoculum from whales which had recently eaten cod and haddock, respectively, were used with krill as substrate.

The flasks were equipped with one-way valves to ensure anaerobic conditions (Tilley $\&$ Terry, 1963). A number of flasks were filled only with inoculum fluid for later analysis of background levels of dry matter. All flasks were then incubated in the dark for either 12 or $24 \mathrm{~h}$ to test the effect of different incubation periods. All incubations took place at $34^{\circ}$, which is the deep body temperature of minke whales (Folkow \& Blix, 1992). Occasionally, all vials were gently shaken during incubation. At the end of incubation the number of culturable viable bacteria was of the same order of magnitude $\left(10^{9} \mathrm{cells} / \mathrm{ml}\right)$ as that found in fresh forestomach fluid. 
After incubation with forestomach inoculum the $\mathrm{pH}$ was measured to confirm that $\mathrm{pH}$ was maintained within the initial range during the first phase of digestion. $\mathrm{HCl}(2 \mathrm{M})$ was then added to each flask to obtain a final concentration of $0.075 \mathrm{M}-\mathrm{HCl}$, resulting in a $\mathrm{pH}$ of $4 \cdot 0-5 \cdot 0$, which is the $\mathrm{pH}$ measured in the ventricle of minke whales (Mathiesen et al. 1990). Pepsin (Sigma; $2900 \mathrm{U} / \mathrm{mg}$ ) was now added to give a final concentration of $0 \cdot 33 \mathrm{~g} / 1$ (Furaya et al. 1979) before all the flasks were incubated for another $12 \mathrm{~h}$ at $34^{\circ}$. Strictly anaerobic conditions are not necessary during this stage.

Finally, concentrated $\mathrm{NaOH}$ was added to give a $\mathrm{pH}$ of $6 \cdot 9-7 \cdot 0$, which is the $\mathrm{pH}$ measured in fresh duodenal contents (Mathiesen et al. 1990), and $27 \mathrm{ml}$ duodenal extract added. The flasks were now all incubated at $34^{\circ}$ for another $12 \mathrm{~h}$, and then frozen at $-20^{\circ}$ until analysis of dry matter content was made.

\section{Insoluble dry matter isolation}

The flasks were later thawed in water $\left(5^{\circ}\right)$ and the contents of each poured into three $50 \mathrm{ml}$ vials. The Erlenmeyer flasks were carefully flushed with cold, distilled water to ensure that no dry matter remained. Experience has shown that it is difficult to filter the samples without previous centrifugation; therefore, the vials were centrifuged for $10 \mathrm{~min}$ at $2500 \mathrm{~g}$ and the supernatant fraction discarded. The precipitate was transferred onto a preweighed glass microfibre filter (Whatman GF/C d: $100 \mathrm{~mm}$ ) in a Büchner funnel connected to a vacuum pump. After filtration the filter with its precipitate was put into a small preweighed Erlenmeyer flask and dried at $95^{\circ}$ for $17 \mathrm{~h}$. Thereafter, the flasks were cooled in a desiccator before being weighed on a calibrated scale (accuracy $\pm 0.1 \mathrm{mg}$ ). The dry matter value was then corrected for background and compared with the dry matter content of the substrate before incubation. The following formula was used for estimation of DMD:

$$
\% \mathrm{DMD}=100-\left(\frac{\mathrm{DM}_{\mathrm{r}}-\mathrm{DM}_{\mathrm{b}}}{\mathrm{DM}_{\mathrm{s}}}\right) \times 100,
$$

where $\mathrm{DM}_{\mathrm{r}}$ is the residual dry matter content after incubation, $\mathrm{DM}_{\mathrm{b}}$ is the dry matter content of background and $\mathrm{DM}_{\mathrm{s}}$ is the dry matter content of fresh substrate at the start of the experiment. $\mathrm{DM}_{\mathrm{s}}$ was calculated by drying a number of preweighed substrate samples at $95^{\circ}$ for $17 \mathrm{~h}$ and expressing dry matter weight as a proportion of fresh 'wet' substrate.

\section{Digestible energy}

The samples of the fresh dried substrate and residual dry matter (after the three-stage incubation) had their energy contents ( $\mathrm{J} / \mathrm{g}$ dry matter) measured using a Gallenkamp automatic adiabatic bomb calorimeter. DE was then calculated as follows:

$$
\% \mathrm{DE}=100-\left(\frac{\left(\mathrm{DM}_{\mathrm{r}}-\mathrm{DM}_{\mathrm{b}}\right) \mathrm{E}_{\mathrm{r}}}{\left(\mathrm{DM}_{\mathrm{s}}\right) \mathrm{E}_{\mathrm{s}}}\right) \times 100,
$$

where $E_{r}$ is the energy content of residual dry matter and $E_{s}$ is the energy content of the substrate.

\section{Statistical analysis}

All values are presented as means and standard deviations, and $n$ is the number of parallels. A Student's $t$ test was used to test the difference between means.

\section{RESULTS}

Most of the dry matter (about $70 \%$ of initial dry matter) of the substrate disappeared into solution by bacterial degradation, during the first phase of the in vitro digestion procedure (Fig. 1), indicating the importance of the forestomach microbial population in energy 


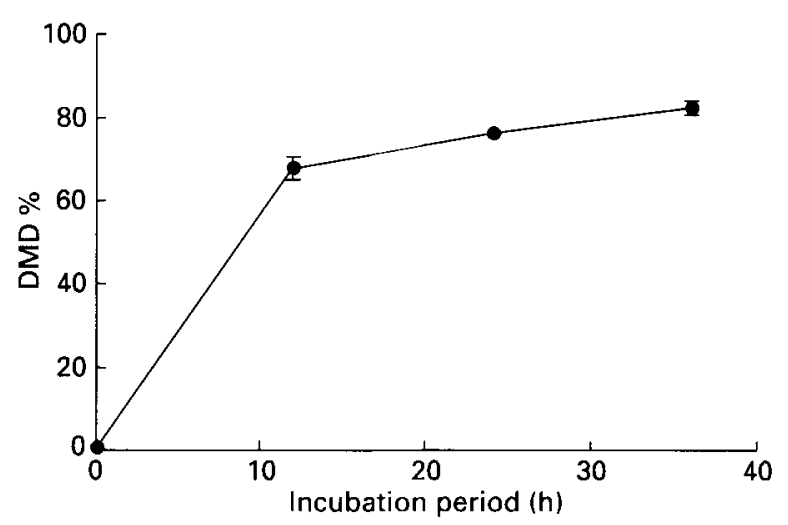

Fig. 1. Typical experiment showing in vitro dry matter disappearance (DMD; \%) of herring (Clupea harengus) by minke whale in relation to the period of incubation (h). A three-stage in vitro test was used to simulate (1) the forestomach microbial fermentation, (2) the enzymic breakdown with pepsin (EC 3.4.23.1)-HCl in the fundic chamber and (3) the duodenal enzymic decomposition of the substrate. Incubation period was $12 \mathrm{~h}$ at each stage.

uptake from prey in minke whales. Changing the incubation period from 12 to $24 \mathrm{~h}$ during the first phase did not increase DMD $(P>0.05)$. The residual material from phase 1 was then further digested using added pepsin and duodenal contents containing enzymes during phases 2 and 3 respectively, further increasing the DMD of the prey (Fig. 1).

DMD of krill based on fresh forestomach and duodenal contents from a whale which had recently eaten krill was 83.4 (SD 4.9$) \%(n 6)$. In this case DE could not be determined due to lack of residual dry matter. The DMD and DE of krill did not differ significantly $(P>0.05)$ when inoculum from whales which had recently eaten cod and haddock was used; therefore, the results of these experiments were pooled. Thus, the DMD of krill was reduced to 73.5 (SD 7.4) \% (n 8), while DE was 70.6 (SD 10.4) \% (n 7). The DMD and DE of herring (Fig. 1) were 80.4 (SD 5.0) \% $(n 18)$ and $92 \cdot 1$ (SD 3.7) \% ( $n$ 16) respectively, when fresh forestomach and duodenal contents from three whales which had recently eaten herring were used.

The energy content of residual dry matter of herring was 11.9 (SD 3.3) $\mathrm{kJ} / \mathrm{g}$ ( $n$ 16) compared with $12 \cdot 1$ (SD $2 \cdot 4) \mathrm{kJ} / \mathrm{g}(n 10)$ in the faeces of whales which had eaten herring.

\section{DISCUSSION}

The three-stage approach to the measurement of the digestibility of different food eaten by minke whales (Nordøy \& Blix, 1992) presented here is derived from the two-stage method of Tilley \& Terry (1963) for ruminants, and the two-stage method of Furaya et al. (1979) and Graham et al. (1989) for pigs. Results obtained by use of these techniques on ruminants and pigs respectively correspond well with those of in vivo tests. In vivo verification of our method in the minke whale is not feasible for obvious technical and logistical reasons; therefore, we have to rely on indirect evidence. First, the appearance and the smell of the krill in the different stages of decomposition during in vitro digestion compare strongly with those of the contents of the corresponding parts of the digestive system of the whale. Second, the energy content of the residual dry matter in our herring experiment was rather similar to that of the faeces of whales which had recently eaten herring.

Our results suggest, therefore, that our measurements are reliable and that the DMD of both krill and herring is about $80 \%$, while DE is in the order of $90 \%$. There are no other digestibility values available for whales, but Ronald et al. (1984) reported a DE of $93 \%$ in 
grey seals (Halichoerus grypus) fed on herring, and Parsons (1977) found a DE of above $90 \%$ in ringed seal (Phoca hispida). Keiver et al. (1984), in the hitherto only study of digestibility of crustaceans in seals, found that the DE of Pandalus borealis in harp seals was less than $72 \%$. This is likely to be lower than the DE of krill in minke whales, and suggests that the microbial fermentation in the forestomach of the whales (Herwig et al. 1984; Herwig \& Staley, 1986; Mathiesen et al. 1990; Olsen et al. 1993) increases the utilization of particularly resistant components such as the chitin skeletons of the krill.

It is also intriguing that the minke whales appear to be able to adapt readily to different types of prey, although the utilization of the new prey at first seems to be somewhat reduced, probably being due to the time taken for the microbial population in the forestomach to adjust to the new substrate.

The authors thank S. D. Mathiesen for fruitful discussions during the planning stages of this project and for assistance during field operations, and Miss M. Alterskjær Olsen for assistance in preparation of the artificial forestomach inoculum. They would also like to express their thanks to the crew of the whaling vessels 'Băragutt' and 'Ann Brita' for cooperation in the field. This study was supported in part by the Norwegian Fisheries Research Council, Marine Mammal Research Programme, grant no. 408.008.

\section{REFERENCES}

Folkow, L. P. \& Blix, A. S. (1992). Metabolic rates of minke whales (Balaenoptera acutorostrata) in cold water. Acta Physiologica Scandinavica 146, 141-150.

Furaya, S, Sakamoto, K. \& Takahashi, S. (1979). A new in vitro method for the estimation of digestibility using the intestinal fluid of the pig. British Journal of Nutrition 41, 511-520.

Graham, H., Løwgren, W. \& Âman, P. (1989). An in vitro method for studying digestion in the pig. 2. Comparison with in vivo ileal and faecal digestibilities. British Journal of Nutrition 61, 689-698.

Herwig, R. P. \& Staley, J. T. (1986). Anaerobic bacteria from the digestive tract of North Atlantic fin whales (Balaenoptera physalus). FEMS Microbiology, Ecology 38, 361-371.

Herwig, R. P., Staley, J. T., Nerini, M. K. \& Braham, H. W. (1984). Baleen whales: preliminary evidence for forestomach microbial fermentation. Applied and Environmental Microbiology 47, 421-423.

Keiver, K. M., Ronald, K. \& Beamish, F. W. H. (1984). Metabolizable energy requirements for maintenance and faecal and urinary losses of juvenile harp seals (Phoca groenlandica). Canadian Journal of Zoology 62, 769-776.

Løwgren, W., Graham, H. \& Aman, P. (1989). An in vitro method for studying digestion in the pig. 1. Simulating digestion in the different compartments of the intestine. British Journal of Nutrition 61, 673-687.

Mathiesen, S. D., Aagnes, T. \& Sørmo, W. (1990). Microbial symbiotic digestion in minke whales (Balaenoptera acutorostrata). Paper SC/42/NHMi9 presented to the IWC Scientific Committee, 1990.

Nordøy, E. S. \& Blix, A. S. (1992). Diet composition of northeastern Atlantic minke whales. Reports of the International Whaling Commission 42, 393-398.

Øien, N. (1991). Abundance of the northeastern Atlantic stock of minke whales based on shipboard surveys conducted in July 1989. Reports of the International Whaling Commission 41, 433-437.

Olsen, M. A., Nordøy, E. S., Blix, A. S. \& Mathiesen, S. D. (1993). Functional anatomy of the gastro-intestinal system of northeasten Atlantic minke whales (Balaenoptra acutorostrata). Journal of Zoology (In the Press).

Parsons, J. L. (1977). Metabolic studies on ringed seal (Phoca hispida). MSc Thesis, University of Guelph.

Ronald, K., Keiver, K. M., Beamish, F. W. H. \& Frank, R. (1984). Energy requirements for maintenance and faecal and urinary losses of the grey seal (Halichoerus grypus). Canadian Journal of Zoology 62, 1101-1105.

Schweder, T., Øien, N. \& Høst, G. (1991). Estimates of the detection probability for shipboard surveys of northeastern Atlantic minke whales, based on a parallel ship experiment. Reports of the International Whaling Commission 41, 417-432.

Tilley, J. M. A. \& Terry, R. A. (1963). A two-stage technique for the in vitro digestion of forage crops. Journal of the British Grassland Society 18, 104-111. 